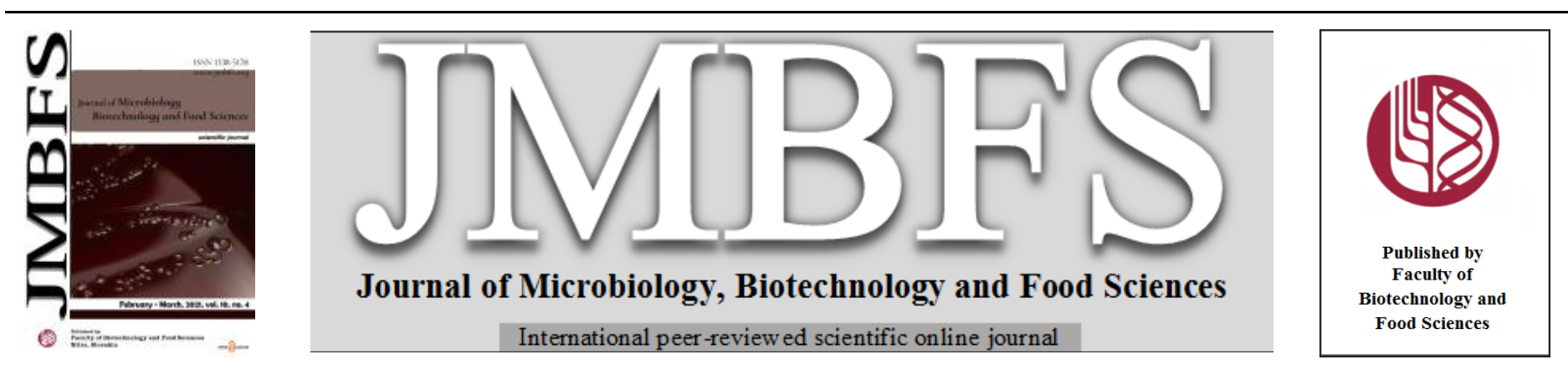

\title{
OPTIMIZATION OF SHOOT INITIATION USING RESPONSE SURFACE METHODOLOGY AND CALLUS MEDIA STANDARDIZATION FOR MICROPROPAGATION OF CENTELLA ASIATICA
}

\author{
Karishma Gururajan, Deeksha Hegde, Sharadhi Udupa, Shobith Shetty and Ujwal P* \\ Address(es): Dr Ujwal P, \\ ${ }^{1}$ Department of Biotechnology Engineering, N.M.A.M. Institute of Technology (Visvesvaraya Technological University, Belagavi), Nitte-574110, Udupi District, \\ Karnataka, India.
}

*Corresponding author: ujwal.p@nitte.edu.in

doi: $10.15414 / j m b f s .2021 .10 .4 .685-690$

ARTICLE INFO

Received 20.12. 2018

Revised 31. 10. 2020

Accepted 9. 11.2020

Published 1. 2. 2021

Regular article

open $\partial$ ACCESS

\begin{abstract}
Centella asiatica, a medicinal herb consumed as a food supplement and used in traditional and folklore medicine is being overexploited for its therapeutic properties. Lack of adequate cultivation and replacement practices could engender the depletion of the wild variety. Application of plant tissue culture has helped in the regeneration and preservation of several plants in-vitro. The present study reports media standardization for micropropagation and callus induction for the conservation of Centella asiatica using field-grown plants. In media standardization for callus induction, appreciable results were obtained where full strength MS (Murashige and Skoog) media was supplemented with $2 \mathrm{mg} . \mathrm{L}^{-1}$ IAA (Indole acetic acid) and a combination of $0.5 \mathrm{mg} . \mathrm{L}^{-1} \mathrm{Kn}$ (Kinetin) with $1 \mathrm{mg} . \mathrm{L}^{-1}$ IAA while MS media supplemented with a combination of $0.5 \mathrm{mg} . \mathrm{L}^{-1} \mathrm{Kn}$ and $1.5 \mathrm{mg} . \mathrm{L}^{-1}$ IAA was used for callus proliferation. Combination of BAP (6Benzyl amino purine) and IAA from preliminary experimentation on micropropagation showed high shooting frequency and were further optimized with parameters such as sucrose and incubation period using Response surface methodology (RSM) to study their individual and interactive effects. A maximum shoot height of $3.8 \mathrm{~cm}$ was obtained from the optimized values after 13 days with both BAP and IAA at $0.5 \mathrm{mg} \cdot \mathrm{L}^{-1}$ and sucrose at $6 \%$ with the $\mathrm{R}^{2}$ value at 0.73 .
\end{abstract}

Keywords: Callus induction, Centella asiatica, Micropropagation, Optimization, Response surface methodology

\section{INTRODUCTION}

Centella asiatica is a small herbaceous annual plant of the family Apiaceae and has been in use as a medicinal herb for thousands of years in folklore medicine and Ayurveda, the Indian system of medicine. It serves as an important component in mixed formulations that helps in gastrointestinal and skin abnormalities along with managing the central nervous system. They have also been considered to be involved in intellect and memory enhancement (Arora $\boldsymbol{e t}$ al., 2002; Gohil et al., 2010). The extensive demand of C.asiatica is met by the naturally growing population. This herb is considered to be one of the primary plants in the International market for the medicinal plant trade. Its overexploitation and unrestricted use may cause a serious decline in the availability of the wild stock (Singh et al., 2010). A futile attempt on its replacement would be a matter of concern for its conservation. Hence, there is an immediate need in identifying techniques that could help in the preservation and regeneration of this herb. Plant tissue culture is one such technique that has been widely used for preservation of such species. Some amount of work on micropropagation (Rao et al., 1999; Das et al., 2008; Naidu et al., 2010) and callus induction, somatic embryogenesis for regeneration of $C$. asiatica have been reported (Patra $\boldsymbol{e t}$ al., 1998; Shashikala et al., 2009).

In practice, trying different combinations of growth regulators and other factors to arrive at optimal levels for the best response, often generates large number of experiments. This is usually carried out by varying a limited number of variables and fixing others arbitrarily at certain levels. Mostly, only one variable is varied at a time and all other variables are held constant. It becomes tedious when many factors are taken into consideration. This method is extremely laborious, time consuming and does not consider the level of interaction among factors, impeding the overall effect on the response. In order to overcome this issue, multivariate statistical techniques for optimization of analytical experiments have been introduced and one such technique is Response surface methodology (Bezerra et al., 2008; Sagwan et al., 2011).

Response surface methodology (RSM) is a collection of mathematical and statistical techniques useful for the modelling and analysis of a process, in which a desired response is affected by several independent factors and the main objective is to optimize this response by optimizing the factors. It helps in determining the effect of independent factors alone or in combination in order to achieve the required outcome (Baş and Boyacı, 2007). In the case of micropropagation, it gives an insight into the interactions of many factors that influence growth and morphogenesis in vitro. Some studies on optimization for shoot and plant regeneration of some important plants have been performed using RSM (George et al., 2000; Chakraborty et al., 2010; Naveenchandra et al., 2011). A standard RSM design called central composite design (CCD) is the most popular technique utilized to design the experiments. These optimization techniques are usually employed once the important factors and their concentration ranges have been identified from preliminary analysis and further optimization is required within the defined factors and concentration range for the desired response (Sagwan et al., 2011).

In this present study, growth parameters and regulators were selected after preliminary studies and optimized for shoot initiation of C.asiatica using Central composite design. Four important factors; BAP, IAA, sucrose, number of days and their range were selected from preliminary experiments which were further optimized in order to obtain a desired response of maximum shoot height. A final experiment on the obtained optimized value was performed and compared with the predicted value. Media standardization was also performed for callus induction, maintenance and proliferation of C.asiatica which could be used for plant regeneration.

\section{MATERIALS AND METHODS}

\section{Selection and sterilization of the explants}

Healthy nodal segments and leaves were selected from field-grown C.asiatica plants collected from a village in Karkala (Udupi district) in Karnataka, India. These explants were washed under running tap water for 20 mins followed by soaking in tween solution (1-2 drops in $100 \mathrm{~mL}$ water) for 10 mins. This was followed by gentle washing with distilled water twice for 10 mins. The explants were then transferred to the laminar hood where they were sterilized with $0.1 \%$ mercuric chloride for 2-3 mins and rinsed thoroughly with sterile distilled water thrice for 5 mins each. 


\section{Media composition for shoot induction}

Full strength Murashige and Skoog (MS) medium was used for micropropagation in the presence of growth hormones in varying concentrations and combinations The hormones used included BAP (6- Benzyl amino purine), IAA (Indole acetic acid), Kinetin (Kn) and 2, 4-dichlorophenoxy acetic acid (2, 4-D). MS media at a $\mathrm{pH}$ of 5.8 (set using either $0.1 \mathrm{~N} \mathrm{NaOH}$ or $\mathrm{HCl}$ ) with required amounts of sucrose and agar was used. Different growth regulators either single or in combination used mainly for shoot induction included: $0.5 \mathrm{mg} . \mathrm{L}^{-1} \mathrm{BAP}, 1 \mathrm{mg} . \mathrm{L}^{-1} \mathrm{BAP}, 1.5$ mg.L ${ }^{-1}$ BAP, 2 mg.L $L^{-1}$ BAP, 2 mg.L. ${ }^{-1}$ IAA, 2.5 mg.L $\mathrm{L}^{-1} \mathrm{Kn}, 1 \mathrm{mg} . \mathrm{L}^{-1}$ BAP with 1 mg.L $L^{-1}$ IAA, $0.5 \mathrm{mg} . \mathrm{L}^{-1}$ IAA with $1.5 \mathrm{mg} . \mathrm{L}^{-1}$ BAP, $1.5 \mathrm{mg} . \mathrm{L}^{-1}$ IAA with 0.5 mg. $\mathrm{L}^{-1}$ BAP, $1 \mathrm{mg} . \mathrm{L}^{-1}$ IAA and $2.5 \mathrm{mg} . \mathrm{L}^{-1} \mathrm{Kn}$. The explants were inoculated into the media aseptically and incubated in a culture room maintained at $24 \pm 2^{\circ} \mathrm{C}$ with $50-60 \%$ relative humidity with 16 hours light.

\section{Media standardization for callus induction}

The surface sterilized explants were inoculated in MS media ( $\mathrm{pH}$ 5.8) supplemented with $2 \mathrm{mg} . \mathrm{L}^{-1}$ IAA individually and a combination of $0.5 \mathrm{mg} . \mathrm{L}^{-1}$ $\mathrm{Kn}$ with $1 \mathrm{mg} . \mathrm{L}^{-1}$ IAA. The inoculated explants were incubated in a culture room maintained at $24 \pm 2{ }^{\circ} \mathrm{C}$ with $50-60 \%$ relative humidity under 16 hours of photoperiodism. The starter callus cultures obtained were subcultured on MS media supplemented with different combinations of growth regulators: $0.5 \mathrm{mg} . \mathrm{L}^{-1}$ Kn with $1.5 \mathrm{mg} . \mathrm{L}^{-1} \mathrm{IAA}, 0.5 \mathrm{mg} . \mathrm{L}^{-1} \mathrm{Kn}$ with $1 \mathrm{mg} . \mathrm{L}^{-1}$ IAA, $2 \mathrm{mg} . \mathrm{L}^{-1}$ BAP with $0.5 \mathrm{mg} . \mathrm{L}^{-1} \mathrm{Kn}, 1.5 \mathrm{mg} . \mathrm{L}^{-1}$ IAA with $0.5 \mathrm{mg} . \mathrm{L}^{-1}$ BAP, $1.5 \mathrm{mg} . \mathrm{L}^{-1}$ IAA with 2 mg. $\mathrm{L}^{-1} 2,4$-D to check the best combination for callus proliferation and maintenance.

\section{Optimization studies using RSM}

CCD is most suitable for fitting a quadratic surface and helps in optimization of effective parameters and their interactions with a series of experiments. A CCD consists of $2^{\mathrm{n}}$ factorial runs with $2^{*} \mathrm{n}$ axial runs and $\mathrm{n}_{\mathrm{c}}$ centre runs. The independent factors selected are studied at five levels $(-\alpha,-1,0,+1,+\alpha)$ (Bezerra et al., 2008). A four factorial five level CCD was implemented in this study in order to obtain a maximum response (y). The four independent variables selected from preliminary experiments for optimization included; A-Incubation time (5 to 15 days), B- Sucrose ( 3 to $6 \%$ ), C- BAP (0.5 to 3 mg.L $\left.{ }^{-1}\right)$, D - IAA (0.5 to 3 $\left.\mathrm{mg} \cdot \mathrm{L}^{-1}\right)$. Table 1 provides details of the variables and levels along with their ranges.

$\underline{\text { Table } 1 \text { Independent variables and levels used for experimental design }}$

\begin{tabular}{|c|c|c|c|c|c|c|}
\hline \multirow{2}{*}{ Variables } & \multirow{2}{*}{ Notations } & \multicolumn{5}{|c|}{ Levels } \\
\hline & & $-\alpha$ & -1 & $\mathbf{0}$ & +1 & $+\alpha$ \\
\hline Number of days, $\mathrm{N}_{\mathrm{d}}$ & A & 5 & 7.5 & 10 & 12.5 & 15 \\
\hline $\begin{array}{l}\text { Sucrose concentration, } \\
\mathrm{S}_{\mathrm{c}}(\mathrm{g} / 100 \mathrm{ml})\end{array}$ & B & 3 & 3.75 & 4.5 & 5.25 & 6 \\
\hline $\mathrm{BAP}\left(\mathrm{mg} \cdot \mathrm{L}^{-1}\right)$ & $\mathrm{C}$ & 0.5 & 1.125 & 1.75 & 2.375 & 3 \\
\hline $\mathrm{IAA}\left(\mathrm{mg} \cdot \mathrm{L}^{-1}\right)$ & $\mathrm{D}$ & 0.5 & 1.125 & 1.75 & 2.375 & 3 \\
\hline
\end{tabular}

As per the experimental design the various combinations of BAP with IAA and sucrose along with the days were analyzed and experiments were conducted in randomized order. The response of the explants was determined by recording the height of the shoot on the set day. The statistical analysis was conducted using Minitab 17, wherein a response surface design was created which provided the coded values and the experiments were conducted based on these coded values. Once the response was obtained, it was analyzed for the significant terms using the ANOVA chart. Table 2 gives the details of the experiments with different parameter combinations performed and the response i.e. height of the plant was recorded which was compared with the predicted value obtained from the software.

The experimental data thus obtained were modeled to second order polynomial equation (Ahmad et al., 2013

$$
\mathrm{y}=\beta_{o}+\sum \beta_{i} x_{i}+\sum \beta_{i i} x_{i}^{2}+\sum \sum \beta_{i j} x_{i} x_{j} \quad \text { Eq. (1) }
$$

where, $\quad y=$ response i.e. height of the explants $(\mathrm{cm})$

$\beta_{0}=$ intercept constant coefficient

$\beta_{i}=$ linear constant coefficient

$\beta_{i i}=$ quadratic constant coefficient

$\beta_{i j}=$ interaction constant coefficient

Table 2 Order of experiments with coded and uncoded variables

\begin{tabular}{|c|c|c|c|c|}
\hline \multirow{2}{*}{ Std order } & \multicolumn{3}{|c|}{ Coded variables (Uncoded variables) } & \multirow[b]{2}{*}{ D } \\
\hline & A & B & C & \\
\hline 1 & $-1(7.5)$ & $1(5.25)$ & $-1(1.125)$ & $-1(1.125)$ \\
\hline 2 & $-1(7.5)$ & $-1(3.75)$ & $1(2.375)$ & $-1(1.125)$ \\
\hline 3 & $1(12.5)$ & $-1(3.75)$ & $1(2.375)$ & $-1(1.125)$ \\
\hline 4 & $1(12.5)$ & $1(5.25)$ & $-1(1.125)$ & $1(2.375)$ \\
\hline 5 & $-1(7.5)$ & $1(5.25)$ & $-1(1.125)$ & $1(2.375)$ \\
\hline 6 & $1(12.5)$ & $1(5.25)$ & $1(2.375)$ & $-1(1.125)$ \\
\hline 7 & $1(12.5)$ & $-1(3.75)$ & $1(2.375)$ & $1(2.375)$ \\
\hline 8 & $1(12.5)$ & $1(5.25)$ & $-1(1.125)$ & $-1(1.125)$ \\
\hline 9 & $-1(7.5)$ & $-1(3.75)$ & $1(2.375)$ & $1(2.375)$ \\
\hline 10 & $1(12.5)$ & $1(5.25)$ & $1(2.375)$ & $1(2.375)$ \\
\hline 11 & $1(12.5)$ & $-1(3.75)$ & $-1(1.125)$ & $-1(1.125)$ \\
\hline 12 & $-1(7.5)$ & $1(5.25)$ & $1(2.375)$ & $1(2.375)$ \\
\hline 13 & $-1(7.5)$ & $1(5.25)$ & $1(2.375)$ & $-1(1.125)$ \\
\hline 14 & $-1(7.5)$ & $-1(3.75)$ & $-1(1.125)$ & $-1(1.125)$ \\
\hline 15 & $2(15)$ & $0(4.5)$ & $0(1.75)$ & $0(1.75)$ \\
\hline 16 & $-2(5)$ & $0(4.5)$ & $0(1.75)$ & $0(1.75)$ \\
\hline 17 & $0(10)$ & $-2(3)$ & $0(1.75)$ & $0(1.75)$ \\
\hline 18 & $0(10)$ & $0(4.5)$ & $0(1.75)$ & $0(1.75)$ \\
\hline 19 & $0(10)$ & $0(4.5)$ & $0(1.75)$ & $2(3)$ \\
\hline 20 & $0(10)$ & $2(6)$ & $0(1.75)$ & $0(1.75)$ \\
\hline 21 & $0(10)$ & $0(4.5)$ & $-2(0.5)$ & $0(1.75)$ \\
\hline 22 & $0(10)$ & $0(4.5)$ & $0(1.75)$ & $0(1.75)$ \\
\hline 23 & $0(10)$ & $0(4.5)$ & $0(1.75)$ & $-2(0.5)$ \\
\hline 24 & $0(10)$ & $0(4.5)$ & $2(3)$ & $0(1.75)$ \\
\hline
\end{tabular}

\section{RESULTS AND DISCUSSION}

Media standardization for callus induction, maintenance and proliferation

In the present study, visible calli began to form on medium that was supplemented with $2 \mathrm{mg} . \mathrm{L}^{-1}$ IAA as well as a combination of $0.5 \mathrm{mg} . \mathrm{L}^{-1} \mathrm{Kn}$ with $1 \mathrm{mg} . \mathrm{L}^{-1}$ IAA (Fig 1). White, compact, nodular callus with embryonic structures developed on the callus periphery were classified as embryogenic callus which continued to develop further. During subsequent sub-culturing and regeneration, some calli turned brown and some turned black due to the accumulation of phenolic components.

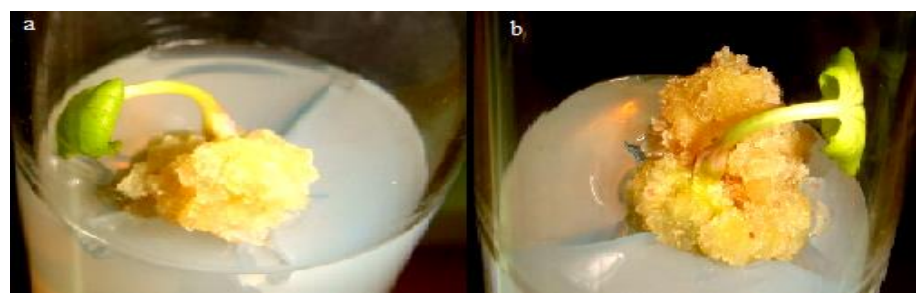

Figure $1(\mathbf{a \& b})$ Callus induction of $C$. asiatica using full strength MS media supplemented with $0.5 \mathrm{mg} . \mathrm{L}^{-1} \mathrm{Kn}$ and $1 \mathrm{mg} . \mathrm{L}^{-1} \mathrm{IAA}$

When the embryogenic callus was sub-cultured on MS media containing a combination of $2 \mathrm{mg} . \mathrm{L}^{-1}$ BAP with $0.5 \mathrm{mg} . \mathrm{L}^{-1} \mathrm{Kn}$, it led to the formation of green callus (Fig 2). Sub-culturing on MS media containing hormones for callusing resulted in proliferation of callus which was sub-cultured every three weeks. Subculturing on media containing 2, 4-D in combination with other hormones showed very poor growth and certain degree of contamination.

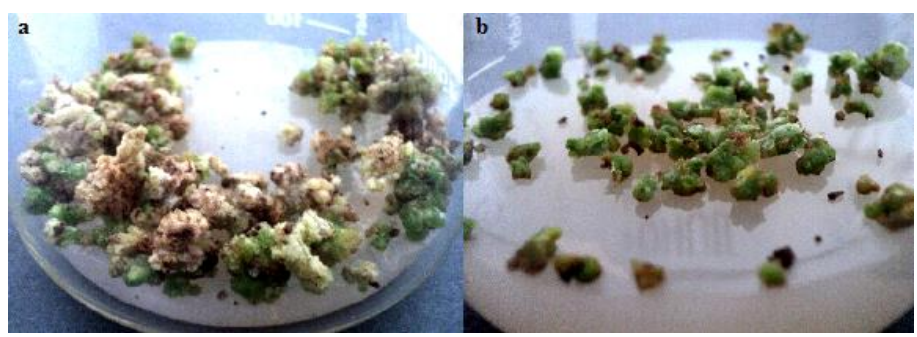

Figure $2(\mathbf{a \& b})$ Establishment and maintenance of callus using full strength MS media supplemented with $2 \mathrm{mg} . \mathrm{L}^{-1} \mathrm{BAP}$ and $0.5 \mathrm{mg} . \mathrm{L}^{-1}$ Kinetin

Overuse of Centella asiatica for its medicinal attributes may lead to depletion of the wild variety in the near future. Hence, methods have to be devised for its timely replenishment and conservation. A successful protocol for the regeneration of callus cultures of C.asiatica was established by Patra $\boldsymbol{e t} \boldsymbol{a l}$. 
(1998) where the stem and leaf explants were cultured on MS media supplemented with $2.0 \mathrm{mg} . \mathrm{L}^{-1} \mathrm{Kn}$ and $4.0 \mathrm{mg} . \mathrm{L}^{-1}$ of NAA. They were regenerated after 4 weeks using $4.0 \mathrm{mg} . \mathrm{L}^{-1} \mathrm{BAP}, 2.0 \mathrm{mg} . \mathrm{L}^{-1} \mathrm{Kn}$, and $0.25 \mathrm{mg} . \mathrm{L}^{-1} \mathrm{NAA}$ and 20 $\mathrm{mg} . \mathrm{L}^{-1}$ adenine sulphate. Studies performed by Rao et al. (1999) showed the best combination of growth regulators was $2 \mathrm{mg} . \mathrm{L}^{-1} \mathrm{NAA}$ with $0.5 \mathrm{mg} . \mathrm{L}^{-1} \mathrm{Kn}$ for leaf base explants where maximum frequency of $88 \%$ was observed. In case of somatic embryogenesis performed by Joshee $\boldsymbol{e t}$ al. (2007), MS basal media with 2, 4-D and 2, 4-D with IAA showed the induction of somatic embryos on stolon tips and leaf explants.

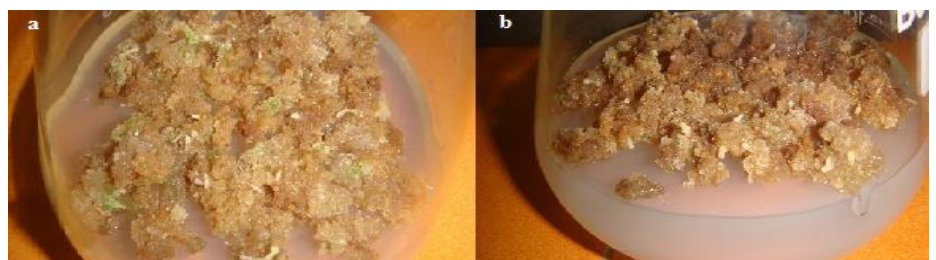

Figure $3(\mathbf{a} \& \mathbf{b})$ Establishment and maintenance of callus using full strength MS media supplemented with $0.5 \mathrm{mg} . \mathrm{L}^{-1} \mathrm{Kn}$ and $1.5 \mathrm{mg} \cdot \mathrm{L}^{-1} \mathrm{IAA}$

In in-vitro callus induction studies performed by Shashikala et al. (2009) on leaf petiole and root explants, MS media supplemented with $0.5 \mathrm{mg} . \mathrm{L}^{-1} \mathrm{NAA}$ with 2 $\mathrm{mg} . \mathrm{L}^{-1} \mathrm{Kn}$ and $0.5 \mathrm{mg} . \mathrm{L}^{-1}$ NAA with $2 \mathrm{mg} . \mathrm{L}^{-1}$ BAP was found to be effective The frequency of callus induction was $75-88 \%$ at the end of fourth week. Media supplemented with 2, 4-D alone or in combination showed $80-84 \%$ frequency bu turned brown after 40 days of incubation. Studies performed by Naidu et al. (2010) showed MS media supplemented with $4 \mathrm{mg} \cdot \mathrm{L}^{-1} \mathrm{NAA}$ in combination with $2 \mathrm{mg} . \mathrm{L}^{-1} 2,4-\mathrm{D}$ proved effective for callus induction with $92 \%$ frequency. Visible calli appeared by $8^{\text {th }}$ day on media supplemented with auxin and proliferated within 12-16 days. After 18 days, two types of callus were observed which were classified as embryogenic and non-embryogenic type. Other studies on callus induction of $C$. asiatica have also been performed (Ram et al., 2014; Rahayu $\boldsymbol{e}$ al., 2016). The presence of auxins or cytokines or a combination of both is generally required for callus initiation. Present study reports the use of $2 \mathrm{mg} . \mathrm{L}^{-1}$ IAA and a combination of $0.5 \mathrm{mg} . \mathrm{L}^{-1} \mathrm{Kn}$ with $1 \mathrm{mg} . \mathrm{L}^{-1} \mathrm{IAA}$ for successful callus induction. From the several combinations tried for callus establishment and maintenance, combined effect of $2 \mathrm{mg} \cdot \mathrm{L}^{-1}$ BAP with $0.5 \mathrm{mg} \cdot \mathrm{L}^{-1} \mathrm{Kn}$ showed the development of green callus. The best response was seen on media supplemented with combination of $0.5 \mathrm{mg} \cdot \mathrm{L}^{-1} \mathrm{Kn}$ and $1.5 \mathrm{mg} . \mathrm{L}^{-1} \mathrm{IAA}$ (Fig 3). These calli could be subsequently transferred to appropriate shooting and rooting medium for effective plant regeneration.

\section{Media standardization for shoot induction}

A protocol was also standardized for shoot initiation using growth regulators individually or in combination. The nodal explants of C.asiatica cultures were successfully established in full strength MS basal medium with hormones. Some loss mostly occurred due to fungal contamination. The various growth hormone combinations and the frequency of shoot initiation are presented in the figure 4 .

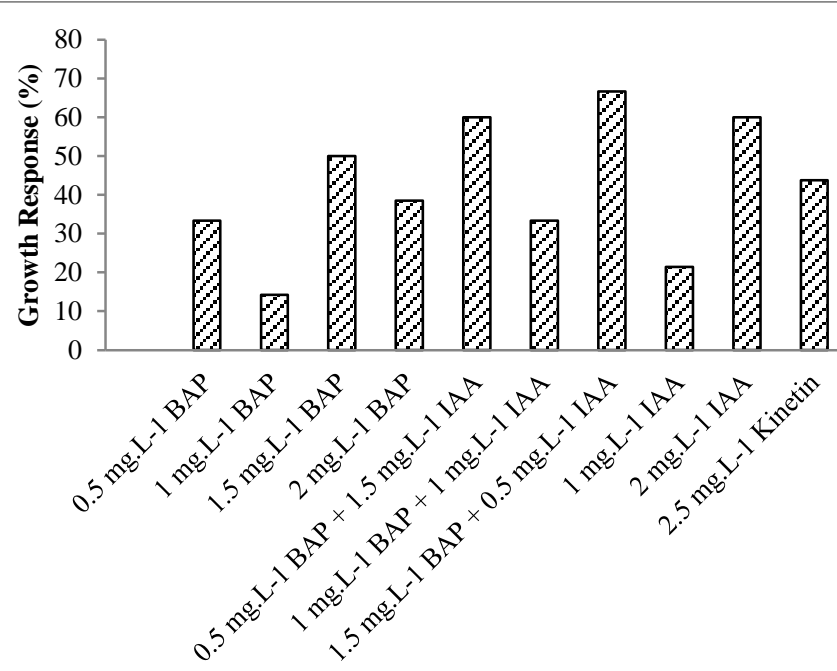

Media Composition

Figure 4 Response of Explants to various hormones in different concentrations and combinations

Effectiveness of BAP on induction of shoot development and multiplication was observed by Karthikeyan et al. (2009) where $2 \mathrm{mg} . \mathrm{L}^{-1}$ produced 15 shoots after 4 weeks along with $2.5 \mathrm{mg} . \mathrm{L}^{-1} \mathrm{Kn}$. $76.67 \%$ of shoot induction was observed on
MS medium augmented with $4 \mathrm{mg} . \mathrm{L}^{-1}$ BAP with $0.1 \mathrm{mg} . \mathrm{L}^{-1} \mathrm{NAA}$ followed by $70 \%$ on medium consisting of $3 \mathrm{mg} \cdot \mathrm{L}^{-1} \mathrm{BAP}$ with $0.1 \mathrm{mg} \cdot \mathrm{L}^{-1} \mathrm{NAA}$ (Das $\boldsymbol{e}$ al . 2008). In the present study, different concentration range of BAP $\left(0.5 \mathrm{mg} . \mathrm{L}^{-1}\right.$ to 2 $\mathrm{mg} . \mathrm{L}^{-1}$ ) showed an effective shoot initiation of $15-50 \%$. In addition, $2 \mathrm{mg} . \mathrm{L}^{-1}$ IAA and $2.5 \mathrm{mg} . \mathrm{L}^{-1} \mathrm{Kn}$ also showed considerable frequency in shoot development with Kn encouraging multiple shoot generation. Although MS medium amended with individual growth regulators showed appreciable results, best results for effective shoot initiation were obtained for combination of BAP and IAA. The combination of $1.5 \mathrm{mg} . \mathrm{L}^{-1}$ BAP with $0.5 \mathrm{mg} . \mathrm{L}^{-1}$ IAA showed best results with $66.67 \%$ frequency followed by a $60 \%$ frequency using a combination of $0.5 \mathrm{mg} . \mathrm{L}^{-1}$ BAP and $1.5 \mathrm{mg} . \mathrm{L}^{-1}$ IAA. Similar studies on shoot induction using growth regulator combination of BAP and IAA have been successfully reported in other plants (Kumar and Singh, 2009; Iqbal et al., 2013; Rajeshbabu et al., 2014)

\section{Response surface methodology for optimization}

RSM (Central Composite Design) could be an effective tool when more than 2 factors are considered for optimization. CCD has been valuable in optimizing parameters involved in range of functions like media optimization, recovery of valuable proteins from waste and degradation of contaminants (Raja and Murthy, 2013; Speck et al., 2016; Shet et al., 2019). Furthermore, optimization of media components is essential in order to elicit a desired response (Das $\boldsymbol{e t} \boldsymbol{a l}$., 2019). From the preliminary experiments, parameters influencing shoot initiation were chosen for further optimization. In addition to growth regulators BAP and IAA, sucrose and incubation period (days) were also considered as suitable factors. Sucrose and glucose are two major carbon sources used for micropropagation where-in sucrose breaks down to glucose and fructose. $90 \%$ of shoot induction was observed in medium containing sucrose and glucose with maximum results seen with sucrose as a carbon source (Hossain et al., 2005). Sucrose was also used as one of the optimizing factors for multiple shoot initiation using RSM by George $\boldsymbol{e t}$ al. (2000). A central composite design was used to develop a second order polynomial equation to best represent the response model. In the present investigation, $\mathrm{CCD}$ was preferred over BBD for optimization due to its robust nature and inclusion of factors at extreme settings, thus generating best fit model (Aanchal et al., 2016; Alrweili et al., 2019). Multiple shoot initiation was observed when the explants were inoculated in certain media composition as per the experimental design. The experiments were conducted in a randomized order and the shoot height was noted after each experiment. A comparison of experimental height and predicted height is given in table 3.

Table 3 Experimental and predicted value of response

\begin{tabular}{lcc}
\hline Std order & \multicolumn{1}{c}{ Response } \\
& Experimental & Predicted \\
\hline 1 & 1.67 & 1.847 \\
2 & 0.95 & 0.955 \\
3 & 1.567 & 1.458 \\
4 & 1.213 & 1.456 \\
5 & 1.2 & 1.324 \\
6 & 1.6 & 1.892 \\
7 & 1.875 & 2.056 \\
8 & 2.8 & 2.35 \\
9 & 1.567 & 1.924 \\
10 & 1.6 & 1.677 \\
11 & 1.55 & 1.916 \\
12 & 1.49 & 1.546 \\
13 & 1.4 & 1.389 \\
14 & 1.45 & 1.413 \\
15 & 1.9 & 1.887 \\
16 & 1.3 & 1.252 \\
17 & 1.9 & 1.701 \\
18 & 1.595 & 1.569 \\
19 & 1.97 & 1.607 \\
20 & 1.738 & 1.756 \\
21 & 1.966 & 1.936 \\
22 & 1.795 & 1.569 \\
23 & 1.4 & 1.532 \\
24 & 1.85 & 1.699 \\
\hline & &
\end{tabular}

\section{Regression and statistical analysis}

The experimental data thus obtained were modelled to second order polynomial equation (Eq.1) using least square technique and the statistical analysis were performed in Minitab 17. The response was to maximize the height of the shoot. The standard ANOVA table helps in determining the relevancy and the significance of the factors governing the quadratic model. It provides the coefficients of each linear term, its quadratic term and the interaction between the factors (Tab 4) 
Table 4 ANOVA table with linear, quadratic and interaction terms after step wise elimination

\begin{tabular}{lccccc}
\hline Source & DF & Adj SS & Adj MS & F-Value & P-Value \\
Model & 10 & 2.21579 & 0.221579 & 3.69 & 0.015 \\
Blocks & 1 & 0.17530 & 0.175302 & 2.92 & 0.111 \\
Linear & 4 & 0.63123 & 0.157807 & 2.63 & 0.083 \\
A & 1 & 0.54705 & 0.547053 & 9.12 & $0.010^{*}$ \\
B & 1 & 0.00380 & 0.003798 & 0.06 & 0.805 \\
C & 1 & 0.06886 & 0.068859 & 1.15 & 0.303 \\
D & 1 & 0.00700 & 0.007003 & 0.12 & 0.738 \\
Square & 2 & 0.10731 & 0.053655 & 0.89 & 0.433 \\
B*B & 1 & 0.03792 & 0.037922 & 0.63 & 0.441 \\
C*C & 1 & 0.09226 & 0.092256 & 1.54 & 0.237 \\
2-Way & 3 & 1.23618 & 0.412061 & 6.87 & 0.005 \\
Interaction & 1 & 0.11897 & 0.118973 & 1.98 & 0.183 \\
A*D & 1 & 0.49458 & 0.494576 & 8.24 & $0.013^{*}$ \\
B*D & 1 & 0.34598 & 0.345979 & 5.77 & $0.032^{*}$ \\
C*D & 13 & 0.77987 & 0.059990 & & \\
Error & 12 & 0.75987 & 0.063322 & 3.17 & 0.416 \\
Lack-of-Fit & 1 & 0.02000 & 0.020000 & & \\
Pure Error & 23 & 2.99566 & & & \\
Total & 1 & & & & \\
\hline P* 0.05 & 1 & & & & \\
\hline
\end{tabular}

$(* \mathrm{p}<0.05$ indicates significance $)$

From the ANOVA chart, the $\mathrm{F}$ value of the model was 3.69 with its p-value below 0.05 indicating the significance of the model term. ' $p$ ' value $(p<0.05)$ is another tool that helps to determine the significance of each term and aids in eliminating the insignificant ones to obtain a statistically significant reduced fit model (Ghate $\boldsymbol{e t}$ al., 2019). If the value is significant $(\mathrm{p}<0.05)$ then it can be made statistically insignificant by removing the possible outliers (Raja and Murthy, 2013). In this study, the F value of the lack of fit was 3.74 and its pvalue higher than 0.05 indicating the lack-of-fit was insignificant. The linear term of number of days along with interaction terms of Sucrose*IAA and BAP*IAA were found to be statistically significant at $95 \%$ confidence interval. The model showed an $\mathrm{R}^{2}$ of 0.7392 which may be due to the lack of reproducibility in the said experimental module which also could be attributed by a lot of other system behavior changes thus representing contaminants as well as errors (Rahman and Amri, 2011; Gomez-Montes et al., 2015) . Dakshayani et al. (2020) has reported similar results on shoot generation of $C$. intybus where the linear and quadratic coefficients of number of days and kinetin as well as the interaction of hormones BAP and Kinetin were significant. The $\mathrm{R}^{2}$ value obtained here was significantly higher than the $\mathrm{R}^{2}$ value of 0.44 obtained for shoot regeneration of Lettuce by Gomez-Montes et al. (2015).

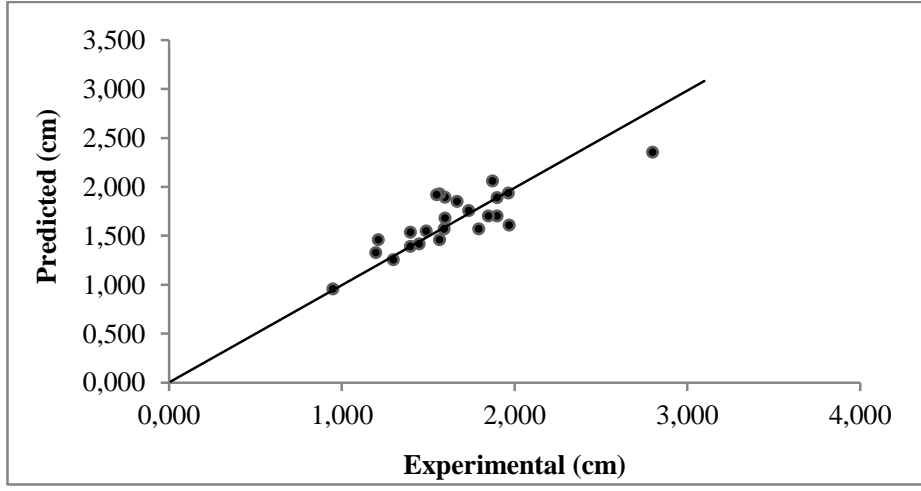

Figure 5 Parity plot showing the distribution of predicted values versus observed values of height in $\mathrm{cm}$

The central composite design provides an empirical relationship between the response (height) and the concluding factors. The parity plot (Fig 5) shows the distribution of the experimental vs predicted value along the $y=x$ line. If more points are clustered along the line, the better is the model designed. The effect of incubation time (A), sucrose concentration (B) with growth regulators BAP $(\mathrm{C})$ and IAA (D) was obtained from the CCD results. The model in terms of its coefficients was best represented by Eq .2 .

Response $=1.5694+0.1587 \mathrm{~A}+0.0139 \mathrm{~B}-0.0592 \mathrm{C}+0.0189 \mathrm{D}+0.0398 \mathrm{~B} * \mathrm{~B}$ $+0.0620 \mathrm{C} * \mathrm{C}-0.0928 \mathrm{~A} * \mathrm{D}-0.2030 \mathrm{~B} * \mathrm{D}+0.1698 \mathrm{C} * \mathrm{D} \ldots \ldots \ldots \ldots \ldots(\mathrm{Eq} .2)$

By observing the experimental and predicted values, it can be indicated that there was a marginal variation in the response value. Hence this proves that the generated model fits significantly well in the present experimentation. The contour plots and the response surface plots helpdetermine the relation and hence the interaction between any two parameters with respect to the response (Fig 6). From the surface and contour plots, when considering the involvement of all the factors, high sucrose concentration and low BAP-IAA levels would be optimum to generate a maximum response. The plot of the significant intercations $(B * D$, $\left.\mathrm{C}^{*} \mathrm{D}\right)$ have been considered in this study $(\mathrm{p}<0.05)$. From the plots of D-IAA and $\mathrm{B}$-sucrose, higher concentration of sucrose and lower concentration of IAA would significantly influence a maximum response and vice-versa. From the plots of IAA and BAP, lower concentration of these growth regulators would help in maximum response.

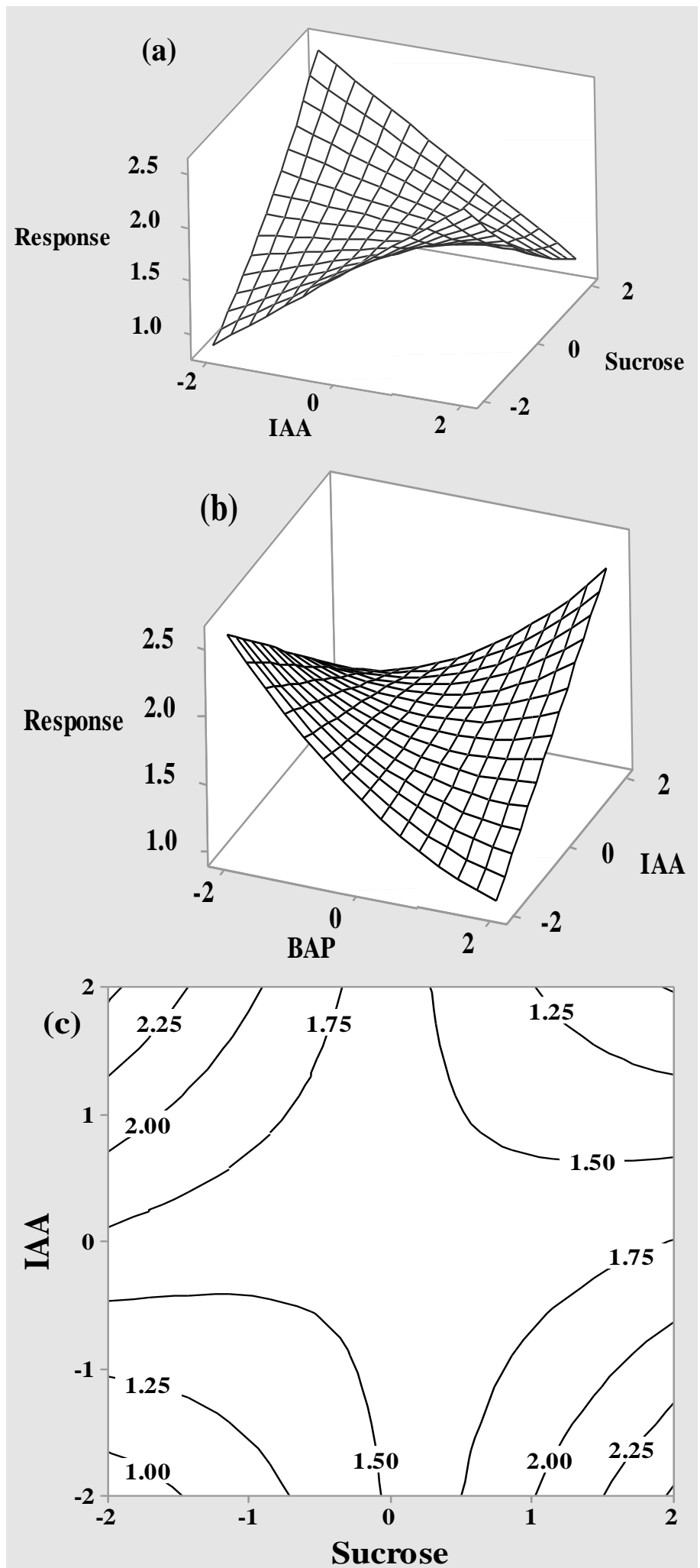




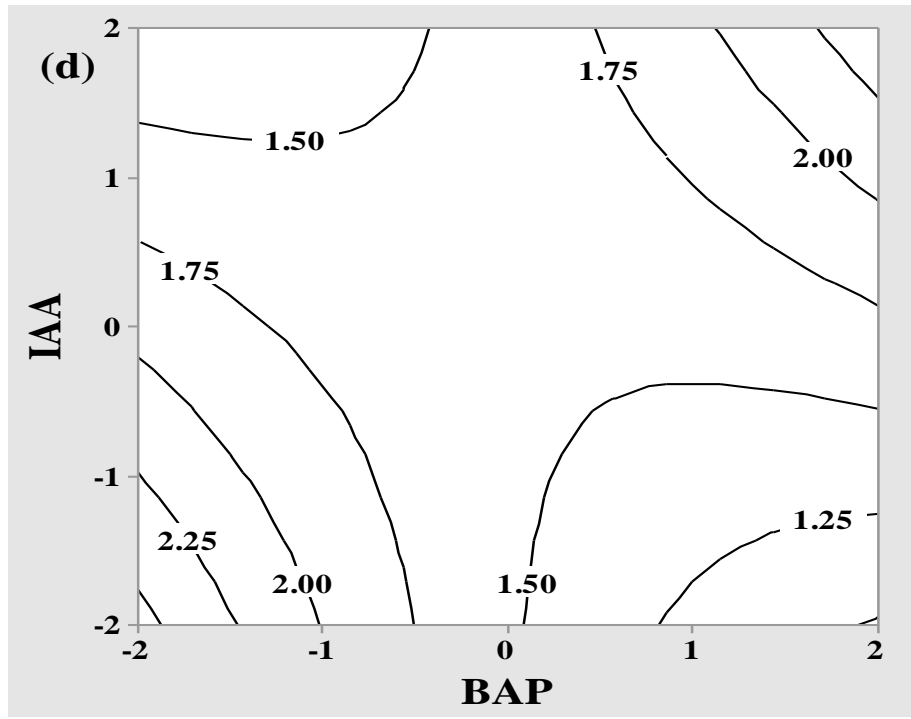

Figure 6 Response surface plots (a\&b) and Contour plots (c\&d) of the significant interactions of factors for maximum shoot height.

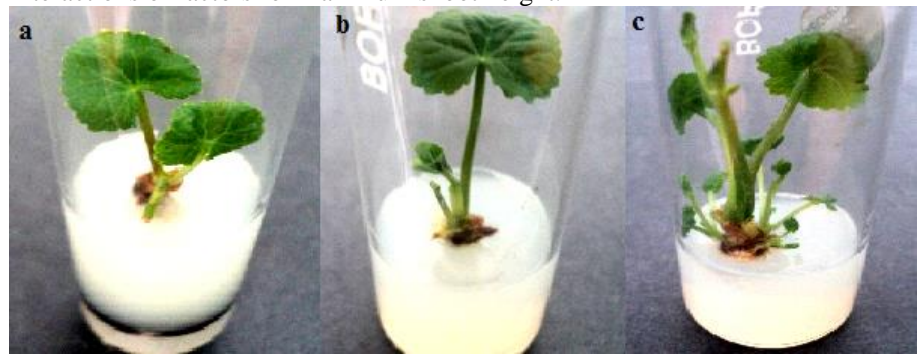

Figure 7 (a,b\& c) Optimization of micropropagation by Response surface methodology using full strength MS media supplemented with BAP and IAA of varying concentrations and varying concentration of sucrose

\begin{tabular}{|c|c|c|c|c|c|}
\hline Parameters & Notations & $\begin{array}{c}\text { Optimized } \\
\text { Coded variables }\end{array}$ & $\begin{array}{c}\text { Optimized } \\
\text { uncoded } \\
\text { variables }\end{array}$ & $\begin{array}{c}\text { Experimental } \\
\text { value }\end{array}$ & $\begin{array}{c}\text { Predicted } \\
\text { value }\end{array}$ \\
\hline Number of days & A & 1.35 & 13 days & \multirow{4}{*}{3.8} & \multirow{4}{*}{4.0} \\
\hline Sucrose & B & 2 & $6 \%$ & & \\
\hline BAP & $\mathrm{C}$ & -2 & $0.5 \mathrm{mg} . \mathrm{L}^{-1}$ & & \\
\hline IAA & D & -2 & $0.5 \mathrm{mg} \cdot \mathrm{L}^{-1}$ & & \\
\hline
\end{tabular}

A final experiment was carried using the optimized values of all the four factors to mainly validate the model. From the response optimzer the coded optimum levels for maximum height is presented in the table 5. Highest concentration of sucrose with low concentration of BAP and IAA yielded optimum results. The optimization helped generate healthy shoots from the explant. In addition to obtaining a good shoot height, it also helped in the initiation and development of multiple shoots (Fig.7). This experiment yielded a height of $3.8 \mathrm{~cm}$ against the predicted height of 4.0. Studies by George et al. (2000) indicated that higher sucrose concentration with low NAA and higher BAP resulted in maximum shoot length. Similar studies have also been done where RSM-CCD was used for the development of cell culture medium of Centella asiatica where the effects of sucrose, IAA and BAP were studied where maximum dry cell weight was obtained at $6 \%$ sucrose and $1 \mathrm{mg} \cdot \mathrm{L}^{-1}$ of BAP and IAA (Omar et al., 2004). Naveenchandra et $\boldsymbol{a l}$. (2011) also observed that maximum sucrose concentration was one of the contributing factors for high shoot initiation. The central composite design (CCD) could be used as a tool to optimize the influential factors and arrive at a desired response. The present study in optimization of parameters affecting micropropagation using response surface methodology yielded healthy in-vitro plants with better shoot height compared to the conventinal method together with development of multiple shoots. To the best of our knowledge there is only a little work observed for media optimization for shoot induction in C.asiatica using RSM. Moreover the RSM method helps to study parameters in concentration ranges otherwise not possible along with studying the interactive effect of two factors. RSM could thus prove to be very helpful in plant tissue culture which otherwise is very tedious with utilization of large quantities of resources. It makes the optimization process less time consuming and cost effective with minimal usage of resources.

\section{CONCLUSION}

Media standardization for callus induction was successfully achieved. MS medium with growth regulators $2 \mathrm{mg} . \mathrm{L}^{-1} \mathrm{IAA} ; 0.5 \mathrm{mg} . \mathrm{L}^{-1} \mathrm{Kn}$ with $1 \mathrm{mg} . \mathrm{L}^{-1} \mathrm{IAA}$ provided the starter callus cultures which were established and proliferated in 0.5 $\mathrm{mg} . \mathrm{L}^{-1} \quad \mathrm{Kn}$ with $1.5 \mathrm{mg} . \mathrm{L}^{-1}$ IAA and subcultured every three weeks. Combination of $2 \mathrm{mg} . \mathrm{L}^{-1} \mathrm{BAP}$ with $0.5 \mathrm{mg} \cdot \mathrm{L}^{-1} \mathrm{Kn}$ generated green callus. Further experimentation on plant regeneration can be performed by using suitable shooting and rooting medium. Best shooting response was observed using combinations of $1.5 \mathrm{mg} . \mathrm{L}^{-1}$ BAP with $0.5 \mathrm{mg} . \mathrm{L}^{-1}$ IAA followed by $0.5 \mathrm{mg} . \mathrm{L}^{-1}$ BAP with $1.5 \mathrm{mg} \cdot \mathrm{L}^{-1}$ IAA. BAP and IAA along with sucrose concentration and incubation period were selected for optimization using RSM to obtain maximum height. The significant factors were determined form the ANOVA chart and the interactive effects of the factors were studied from the contour and response surface plots. An optimized value of BAP and IAA each at $0.5 \mathrm{mg} . \mathrm{L}^{-1}$, sucrose at $6 \%$ and incubation period of 13 days gave a height of $3.8 \mathrm{~cm}$ against the predicted 4.0. In addition to a good shoot height, multiple shoot initiation was also observed. This combination of growth regulators could be used as an alternative for $C$.asiatica regeneration thereby helping in its conservation.

Acknowledgement: Authors are thankful to the Department of Biotechnology Engineering and the Principal NMAMIT, Nitte for all the support.

\section{REFERENCES}

Aanchal., Akhtar, N., Kanika., Goyal, D., \& Goyal, A. (2016). Response surface methodology for optimization of microbial cellulase production. Romanian Biotechnological Letters, 21(5), 11832-11841.

Ahmad, R., Al-Shorgani, N.K.N., Hamid, A. A., Mohtar, W., Yusoff, W., \& Daud, F. (2013). Optimization of Medium Components Using Response Surface Methodology (RSM) for Mycelium Biomass and Exopolysaccharide Production by Lentinus Squarrosulus. Adv Biosci Biotechnol, 4,1079-1085 http://dx.doi.org/10.4236/abb.2013.412144

Alrweili, H., Georgiou, S., \& Stylianou, S. (2019). Robustness of response surface designs to missing data. Quality and Reliability Engineering International, 35(5), 1288-1296. https://doi.org/10.1002/qre.2524

Arora, D., Kumar, M., \& Dubey, S. D. (2002). Centella Asiatica - A Review of Its Medicinal Uses and Pharmacological Effects. J Nat Remedies, 2(2), 143 149. https://doi.org/10.18311/jnr/2002/144

Bas, D., \& Boyaci, İ.H. (2007). Modeling and Optimization I: Usability of Response Surface Methodology. J. Food Eng, 78(3), 836-845. http://dx.doi.org/10.1016/j.jfoodeng.2005.11.024

Bezerra, M.A., Santelli, R.E., Oliveira, E.P., Villar, L.S., \& Escaleira, L. A. (2008). Response Surface Methodology (RSM) as a Tool for Optimization in Analytical Chemistry. Talanta, 76(5), 965-977. https://doi.org/10.1016/j.talanta.2008.05.019

Chakraborty, D., Bandyopadhyay, A., Bandopadhyay, S., Gupta, K., \& Chatterjee, A. (2010). Use of Response Surface Methodology for Optimization of a Shoot Regeneration Protocol in Basilicum Polystachyon. In Vitro Cell Dev Biol Plant, 46(5), 451-459. http://doi/org/10.1007/s11627-010-9309-4

Das, D., Selvaraj, R., \& Bhat, R,M. (2019). Optimization of inulinase production by a newly isolated strain Aspergillus flavus var. flavus by solid state fermentation of Saccharum arundinaceum. Biocatalysis and Agricultural Biotechnology, 22, 101363. https://doi.org/10.1016/j.bcab.2019.101363

Das, R., Hasan, M. F., Hossain, M. S., \& Rahman, M. (2008). Micropropagation Of Centella Asiatica L. An Important Medicinal Herb. Progressive Agriculture, 19(2), 51-56. http://dx.doi.org/10.3329/pa.v19i2.16928

Dakshayini., Goveas, L.C., Prasad, M., \& Ujwal, P. 2020. Optimization of Direct Shoot Regeneration Using Leaf Explants from Cichorium intybus by Response Surface Methodology. Studies in Indian Place Names, 40(7), 602 - 614.

Geethu, M., Vrundha, R., Raja, S., Chandrashekar, R, H., \& Divyashree, M.S. (2019). Improvement of the Production and Characterisation of Polyhydroxyalkanoate by Bacillus endophyticus Using Inexpensive Carbon 
Feedstock. Journal of Polymers and the Environment, 27(5), 917-928. https://doi.org/10.1007/s10924-019-01397-z

George, J., Bais, H P., Ravishankar, G. A., \& Manilal, P. (2000). Optimization of Media Constituents for Shoot Regeneration from Leaf Callus Cultures of Decalepis Hamiltonii Wight. and Arn. HortScience, 35(2), 296-299. https://doi.org/10.21273/HORTSCI.35.2.296

Ghate, V. M., Kodoth, A. K., Raja, S., Vishalakshi, B., \& Lewis, S. A. (2019) Development of MART for the Rapid Production of Nanostructured Lipid Carriers Loaded with All-Trans Retinoic Acid for Dermal Delivery. AAPS PharmSciTech, 20(4). https://doi.org/10.1208/s12249-019-1307-1

Gohil, K.J., Patel, J.A., \& Gajjar, A.K. (2010). Pharmacological Review on Centella Asiatica: A Potential Herbal Cure-All. Indian J. Pharm. Sci, 72(5), 546556. doi:10.4103/0250-474X.78519.

Gómez-Montes, E. O., Oliver-Salvador, C., Durán-Figueroa, N., Badillo-Corona, J. A., \& Salas, C. E. (2015). Optimization of direct shoot regeneration using cotyledonary explants and true leaves from lettuce cv. Romaine (Lactuca sativa L.) by surface response methodology. Plant Growth Regulation, 77(3), 327-334. https://doi.org/10.1007/s10725-015-0067-5

Hossain, M. A., Hossain, M.T., Ali, M.R., \& Rahman, S.M.M. (2005). Effect of Different Carbon Sources on in vitro Regeneration of Indian Pennywort (Centella Asiatica L.). Pak J Biol Sci, 8(7), 963-965. DOI: 10.3923/pjbs.2005.963.965

Joshee, N., Biswas, B. K., \& Yadav, A. K. (2007). Somatic Embryogenesis and Plant Development in Centella Asiatica L ., a Highly Prized Medicinal Plant of the Tropics. HortScience, 42(3), 633-637. https://doi.org/10.21273/HORTSCI.42.3.633

Karthikeyan, K., Chandran, C., \& Kulothungan, S. (2009). Rapid Clona Multiplication through in vitro Axillary Shoot Proliferation of Centella Asiatica

L. Indian J. Biotechnol, 8(2), 232-235.

Kumar, S., \& Singh, N. (2009). Micropropagation of Prosopis Cineraria (L.) Druce- A Multipurpose Desert Tree. Researcher, 1 (3), 28-32.

Iqbal, M.M., Muhammad, A., Hussain, I., \& Bilal, H. (2013). Optimization of In Vitro Micropropagation Protocol for Banana (Musa Sapientum L.) Under Different Hormonal Concentrations and Growth Media. IJAIR, 2 (1), 23-25.

Naidu, T. B., Rao, S.N.N., Mani, S., Mohan, Y. S. Y .V. J., \& Pola, S. (2010), Conservation of an Endangered Medicinal Plant Centella Asiatica through Plant Tissue Culture. Drug Invent Today, 2(1), 17-21.

Naveenchandra, P. M., Bhattacharya, S., \& Ravishankar, G.A. (2011). Culture

Media Optimization through Response Surface Methodology for in vitro shoot bud development of Solanum Melongena L . for Micropropagation. Int.J.Bio Automation, 15(3), 159-172.

Omar, R., Abdullah, M. A., Hasan, M. A., \& Marziah, M. (2004). Development of Growth Medium for Centella Asiatica Cell Culture via Response Surface

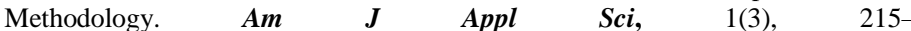
219. https://doi.org/10.3844/ajassp.2004.215.219

Patra, A., Rai, B., Rout, G.R., \& Das, P. (1998). Successful Plant Regeneration from Callus Cultures of Centella Asiatica (Linn.) Urban. Plant Growth Regul, 24 13-16. http://doi/org/10.1023/A:1005932313180

Rahayu, S., Roostika, I., \& Bermawie, N. (2016). The Effect of Types and Concentrations of Auxins on Callus Induction of Centella Asiatica. Nusantara bioscie, 8(2), 283-287. https://doi/org/10.13057/nusbiosci/n080224

Rahman, M., \& Amri, A. (2011). Effect of outlier on coefficient of determination. International Journal of Education Research, 6(1), 9-20.

Raja, S., \& Murty, V.R. (2013). Optimization of Aqueous Two-Phase Systems for the Recovery of Soluble Proteins from Tannery Wastewater Using Response Surface Methodology. Journal of Engineering (United States), 2013, [217483]. https://doi.org/10.1155/2013/217483

Rajeshbabu, P., Gopalakrishnan, M., Janarthanan, \& B., Sekar, T. (2014). An Efficient and Rapid Regeneration Protocol for Micropropagation of Rosa Bourboniana from Nodal Explants. Int.J.Curr.Biotechnol., 2(1), 24-29.

Ram, A. T., Koorikkadan, \& M. S., Kuniyil, P. (2014). Development of a Simple, Reproducible and Efficient in vitro Culture Protocol for Callus Proliferation under Varying Concentrations of 6-Benzylaminopurine (BAP) via Leaf and Nodal Segments. Int.J.Curr.Biotechnol., 2 (6), 1-4.

Rao, K. P., Rao, S. S., \& Sadanandam, M. (1999). Tissue Culture Studies of Centella Asiatica. Indian J Pharm Sci, 392-394.

Sagwan, L. A., Survase, S. A., \& Annapure, U. S. (2011). Application of Response Surface Methodology for Production of Capsaicin from Capsicum Annum L . International Journal of Biotechnology Research, 4(1), 11-18.

Shashikala, C.M., Shashidhara, S., \& Rajshekharan, P.E. (2009). In Vitro Callus Culture of Centella Asiatica L . ( Urb .) and Its HPLC Analysis. Biosci Biotechnol Res Asia, 6(2), 863-868.

Shet, V. B., Rakshith, K. G., Shetty, N. J., Shetty, V. C., Siddik, A., Goveas, L. C., Rao, V. C., \& Ujwal, P. (2019). The application of Response surface methodology for the Optimization of autoclave assisted $\mathrm{HCl}$ hydrolysis of an agro residue cocoa pod shells for releasing reduced sugars. J Microbiol Biotech Food Sci, 9(3), 548-551. doi: 10.15414/jmbfs.2019/20.9.3.548-551

Singh, S., Gautam, A., Sharma, A., \& Batra, A. (2010). Centella Asiatica (L.): A Plant with Immense Medicinal Potential but Threatened. Int J Pharm Sci Rev Res, 4 (2), 9-17.
Speck, F., Raja, S., Ramesh, V., \& Thivaharan, V. (2016). Modelling and Optimization of Homogenous Photo-Fenton Degradation of Rhodamine B by Response Surface Methodology and Artificial Neural Network. Int. J. Environ. Res, 10(4), 543-554. https://doi.org/10.22059/ijer.2016.59683 